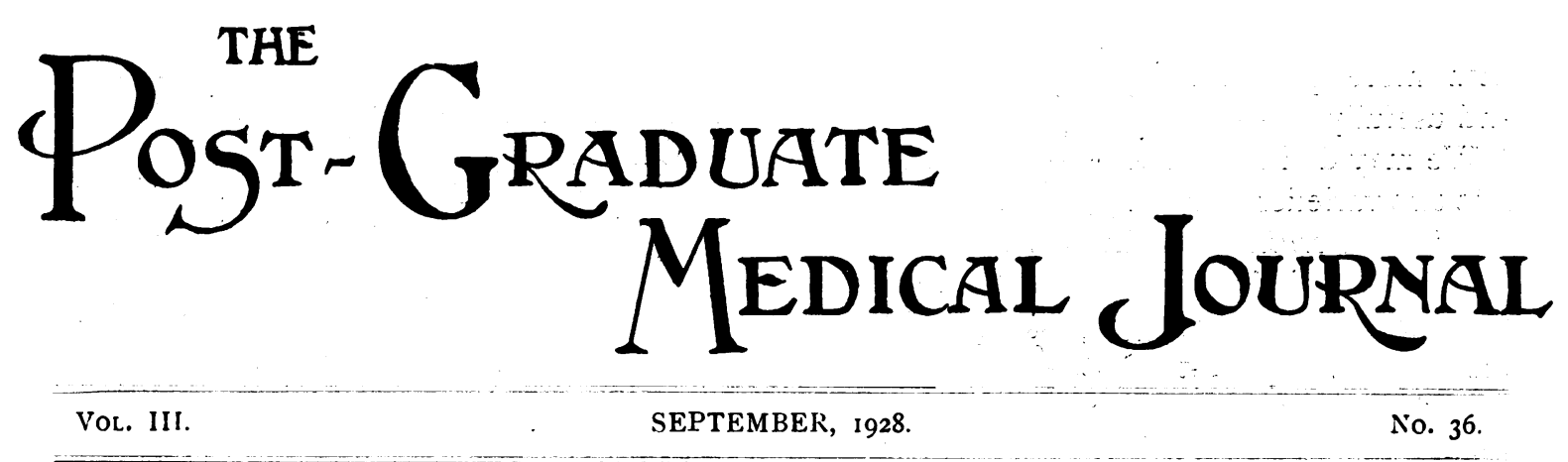

\title{
CONTENTS
}

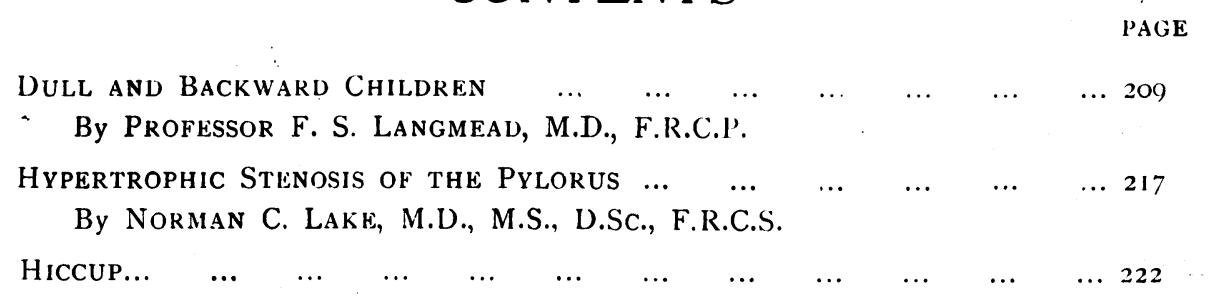

By Robert Hutchison, M.D., F.R.C.P.

$\begin{array}{lllllllllllll}\text { EdtTORIAL } & \text { NOTES } & \ldots & \ldots & \ldots & \ldots & \ldots & \ldots & \ldots & \ldots & \ldots & \ldots & 225\end{array}$

$\begin{array}{lllllllllllll}\text { POST-GRAdUAte NewS } & \ldots & \ldots & \ldots & \ldots & \ldots & \ldots & \ldots & \ldots & \ldots & 226\end{array}$

$\begin{array}{llllllllllllll}\operatorname{INDEX} & \ldots & \ldots & \ldots & \ldots & \ldots & \ldots & \ldots & \ldots & \ldots & \ldots & \ldots & \ldots & 227\end{array}$

Fellowship of Medicine and Post-Graduate Medical Association.-

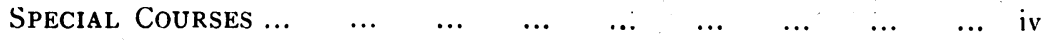

\section{DULL AND BACKWARD CHILDREN.}

\author{
By Professor F. S. LANGmead, \\ M.D., F.R.C.P.,
}

Director of Medical Clinic. St. Mary's Hospital.

THE terms "backward" and "dull" are purely arbitrary and signify merely, when applied to a child, that the individual using them regards the child as below the normal standard in mental attainments. They have a different meaning when used by different observers. Thus, the school teacher will give an educational value and will often dub a child as dull and backward if his educational standard is low in certain aspects, for instance, if he fails to make progress in reading or spelling, or fails to appreciate the value of figures. The same child, as judged by his capabilities other than those in scholastic subjects, may be an average or even exceptionally useful citizen. In this lecture I propose to use the words "backwardness" and "dullness" in their broadest meaning, and not merely in a scholastic sense. In the great majority of cases backwardness in school attainments and the general mental outfit are correspondingly weak, but in some the failure to progress at school is due to a lack of certain mental attributes distinct from inental backwardness considered as a whole.

Regarding backwardness in this broad sense, we may next consider how its examples can be classified, for by some classification we can, I think, approach the subject 
with more precision, and so more clearly and usefully.

We may divide mental backwardness first into two varieties, which I will call "essential" and " non-essential" backwardness.

The essentially backward children are those who are born with brains incapable of mental development up to the standard regarded as average. The backwardness is innatc, the children being potentially backward from birth.

By " non-essential ' backwardness I mean backwardness which is due, not to some inherent defect, but to environmental or other causes to which the child is subjected. These children are born with a potential mental capacity equal to the average, but circumstances prevent or delay its development.

I will now consider these two groups in more detail.

\section{(I) ESSENTIAL BACKWARDNESS.}

With this group I am not to-day very closely concerned in this lecture. It is composed largely of examples of children who, if somewhat more lacking in mentality, would be called mentally deficient or aments. Amongst these essentially backward children must beincluded those affected by microcephaly and mongolism to a slight degree. The microcephalic, with characteristic narrow forehead, roof-shaped vault and very small circumferential cranial measurement, who, if capable of standing, takes up an animal-like pose, which has even led to the subdivision of microcephalics according to the animals they suggest, is usually an idiot or imbecile. The " mongol," with characteristic features of brachycephaly, almond eyes, projecting granular or fissured tongue, frequent grimacing and hypotonia, is usually an imbecile in the category of children regarded according to their talents. But both these disorders in mild degrees may be accompanied by mental poverty which could be called merely dullness or backwardness, a few physical features in each case indicating the group to which it belongs. The child with hydrocephalus is often no more than slightly defective mentally, and is apt to be more hampered by his physical defects than by those of his mind. The large group which has been headed paralytic amentia is a very composite one. It comprises children who have spastic paralysis due to want of cortical development, and also those whose brains have suffered damage in early life, perhaps at birth by trauma, or later from infective, toxic or vascular processes. Of this mixed group, the children whose defect is in development are lowest in the mental scale and least capable of improvement. They are generally below the level of mere dullness. The macrocephalic and amaurotic family idiots are never outside the pale of severe mental deficiency.

Children whose mental weakness is consequent upon ductless gland defect are a class to themselves, for although the error is usually developmental it is not one primarily of the brain. The best known example, the cretin, if frankly so physically, is equally frankly a low-grade ament, and hence outside the scope of this lecture, but mild examples of hypothyroidism, or treated cretins, provide much slighter deviation from the average. Less common defects of this order are those of the pituitary, suprarenal, and genital glands.

The influence of syphilis in the production of dull and backward children is difficult to compute. If only those be regarded as syphilitic who have the physical stigmata of that disease, its incidence is small and amounts to not more than 2 or 3 per cent. of mentally defective children. But in these cases the infection is acquired within the uterus, the fœtus being infected from the mother's blood. 'The frequency with which syphilis in the parents affects the germinal bioplasin, and leads to the birth of a mentally defective or merely dull child, is probably greater, for a positive Wassermann reaction is oblained amongst many in insti- 
tutions who have no physical signs of the disease.

There remains the large mass of mentally weak children who are unclassifiable on ætiological grounds, or on grounds of physical development, to whom the term " simple" or "genetous" mental deficiency has been applied. Within this group are all grades of defect from idiocy to slight dullness. They can be subdivided only according to their talents into idiots, imbeciles, feeble-minded and dull, or according to some special characteristics as excitable, fatuous, destructive or apathetic, \&c. While some of these show the physical stigmata accompanying mental degeneration, such as misshapen heads, large, distorted and projecting ears, highly-arched and narrow palates, and certain peculiarities of pose, combined with obvious lack of attention and inability to concentrate, others may appear quite normal to ordinary examination, and are only recognizable by questioning themselves, their parents and their teachers, or by the application of psychological or educational tests, such as those devised by Binet. The apparent alertness and brightness of mien and attitude of some of these children is very deceptive, and it comes as a surprise to find that their quick and ready answers are invariably wrong and reveal a serious lack in association of ideas.

\section{(2) Non-Essential Dullness AND BACKWARDNESS.}

Let us now turn to the cases of what J have called non-essential backwardness, or backwardness not due to any defect in the brain itself. It is to these I wish particularly to draw your attention, for they are those which are most important for us, as practising physicians, to recognize. Due recognition and treatment may lead to such improvement that a special school or system of education recedes from the offing. Every child who is reported upon as being backward, either by parents or teachers, should be examined and considered from both points of view, physical and environmental, to see whether the backwardness cannot be explained on grounds other than primary mental defect, for it is a serious error to place a child whose backwardness is temporary or capable of correction among others worse mentally equipped than themselves, and from whom no progress can be expected other than that which age itself brings. Once a child such as this is labelled mentally defective or even a dullard, the mantle of inferiority is apt to be assumed for good and the incentive to improvement to be lost. Should he be an attendant at one of the public elementary schools, I am distinctly opposed to sending him to a special school for a probationary period, in the hope that he may improve and be transferred back, for the labelling as defective and the association with those wloo are essentially so is almost a guarantee against improvement. The same is true of children of higher social grades if sent to many of the private schools for backward children. This criticism is, of course, no longer valid if they are sent to schools whose scholars are in the same category as themselves.

I will now consider these examples of symptomatic or non-essential backwardness under two main heads :-

(A) Those related to environment.

(B) Those ascribable to physical defects.

(A) Under environment I include insufficient food and sleep, overwork and poor hygiene. They are, in the main, the attributes of poverty and therefore apply especially to the children of the public elementary schools. I need not emphasize the ill-effect upon mental growth of lack of sufficient and suitable food, and the treatment is obvious in the provision of school meals. The only danger is that the cause may go unrecognized, for these children are apt to be very adverse to admitting poverty, and give an account of meals which exist only in their imagination. The number of 
hours of sleep and recreation are always worthy of inquiry, even in the case of those who are not poor. In the greater freedom which it is now the fashion to give to children seems to be included a compliance with the old-established disinclination to go to bed. In other instances bed-time is regarded as a charre to continue an exciting story to the bitter end, to solve a puzzle or pursue a hobby. Among the poor it may be that bed-time coincides with the return of father or mother late from work. Concerning overwork in the child, I do not mean overwork at school but overwork when that done at home is added. "All work and no play makes Jack a dull boy" is, in these days when paid work out of school hours is illegal, a maxim fairly well complied with, but it is often not applied to Jill. The girl is often kept busy every hour of the day, while the boy out of school hours joins others in their games. If continued, such persistent work leads surely to delay in mental progress.

Among similar causes, I will only mention one other, viz., lack of fresh air and sunlight. The pale, dull and listless dweller in the basement is often recognizable at sight, and in such cases I have frequently heard statements of backwardness at school or of teacher's complaints of actual deterioration of work during the winter months. A special report to the local housing authority that the need for new quarters is pressing has, I am glad to say, usually met with a sympathetic response, and the improvement in mental as well as physical health is patient.

(B) Backwardness due to Physical DEFECT. - It is clear that bodily maladies may delay mental development in several ways. They may, by their chronicity or frequent repetition, so interfere with school attendance or hours of study that the child is always behind. Such a child is backward, but when his health is again restored or during a period of intermission is not dull. He will, however, appear dull if forced into school work when he should be convalescing. Two outstanding examples of diseases which seriously reduce the time for education are chorea and asthma. Both frequently recur, and in both the period of unavoidable abstention from school work is apt to be protracted. Yet these children are bright rather than dull, set back though they may be. In fact, it is rather surprising how well, in many cases, their naturally active minds manage to acquire knowledge up to the average standard, or even beyond. Again, bodily disorders may obstruct understanding by blocking the avenues by which knowledge is received (sense deprivation), or may be of such a kind that it interferes with development as a whole (infantilism). Another interference with education which may be caused by even such minor ailments as toothache is loss of sleep. Let us consider some of these effects of bodily disorders on mental growth in greater detail.

\section{( I) Sense Deprivation.}

There is no better example of the neect for detailed medical examination than sense deprivation. If undetected, it may lead to a gross error in judgment as to the potential mental ability, and may even cause the child to be labelled definitely mentally defective. Here, if the sense deprivation be unmixed with other defects, there is no essential mental weakness, the brain is ready for impressions which it fails to receive, and mental growth is stagnant or delayed. Perhaps the best known case of this kind to be found in the literature is that of Helen Keller. The able mind of this talented authoress, who 은 was both blind and deaf, and being deaf was $\frac{7}{0}$ dumb, was awakened into activity and grew by being approached and trained through $N$ other senses by a persevering and devoted $N$ teacher. Such extreme cases are, of course, $\underset{\omega}{N}$ exceptional and not likely to go undetected. The child, totally blind or totally deaf, is early separated out for special education. $\stackrel{\oplus}{\rightarrow}$ Minor degrees of defective hearing and sight 7 more easily escape detection and may do so, $\frac{\bar{Q}}{\mathbb{D}}$ 
even at the present time, when systematic. examinations of them are practised in most schools. This is particularly true of minor degrees of hypermetropia and astigmatism. The extent to which hypermetropia can be compensated for by muscular effort is so considerable that the child passes the somewhat rough and ready and infrequent school tests. Yet the effort necessary to follow the school work brings exhaustion, and lack of attention and concentration follow close. An imperfect appreciation of what is being written or read, headache from eye-strain, and the consequent exhaustion so hamper and isolate the child that it loses ground and is grouped among the backward.

Some degree of sense deprivation is experienced by the child paralysed from birth or in early life, for it loses the mind-developing influence of muscular movement and the recognition of the size, shape, weight and character of objects by touch. Only in severe cases of paralysis is it likely that this plays a decided part in backwardness. In spastic paralysis in children, for this is the form of paralysis with which mental defect and backwardness are associated, there is more than simply sense deprivation to be considered. In some, as is mentioned above, there is congenital lack of cerebral development ; in these the degree of defect is considerable, and the prospect of improvement slight. In others there is a traumatic, infective, toxic or vascular lesion of a previous healthy brain-here there is considerably more hope of improvement and more scope for education, but the normal level of mental development is not to be confidently expected.

\section{(2) Tonsils and Adenoids.}

The slow, listless, dull stupidity associated with serious degrees of mouth-breathing, the result of naso-pharyngeal obstruction, is well known and has been called "aprosexia." Sleep does not refresh them, for during it they show evidence of considerable oxygen deprivation in blueness and turgidity of the lips and face. They are restless and their nights are full of dreams. In the morning they are tired, refuse their breakfasts, and go reluctantly and wearily to school, with minds far from receptive. Perhaps there is also defective hearing. The treatment for such I need not emphasize, for it is obvious.

\section{(3) Duclless Gland Defects.}

These have already been referred to. I only mention them here again to point out the need for bearing them in mind, especially when backwardness is accompanied by unusual retardation of growth or by special peculiarity in development. For the small, square, fat child, with broad short fingers and dry skin, or the undersized child with alopecia, it is worth while to try the effect of thyroid medication, even though neither in bodily features nor in mental qualities can he be called a cretin. The obese children generally regarded as suffering from dyspituitarism are not backward as a rule in my experience, but on the contrary more often precocious, the full picture of Fröhlich's disease, with its retarded physical and mental growth, being comparatively uncommon. There are, however, slim " childish" boys, small for their age, taking no interest in games, whose mental outlook and school attainments are retarded like their growth, who appear to benefit by protracted treatment by extract of whole pituitary gland.

\section{(4) Infantilism.}

As commonly used to-day, the term infantilism has come to have a somewhat broad and, as many consider, erroneous implication. I ain using it here in reference only to children who in body and mind are retarded in growth, but mentally would pass as normal for an earlier age. Even from this standpoint the scope for the term is large, for serious disorder of any important organ reacts upon the organism as a whole, stunting both body and mind to various degrees. Omitting primary disorders of the brain 
which fall within the pale of "essential" backwardness, and also ductless gland diseases of which I have just spoken very briefly, I will now consider some of the best known examples of infantilism due to visceral disease.

(I) Renal Infantilism.-Here the child is likely to be indeed miniature, with mind not equal to its age, but somewhat more developed than its body. It may even pass for precocious if the intellect be taken in comparison with stature instead of with age. A history of polyuria and polydipsia may be procurable, and examination may reveal the cardiac and vascular changes consequent upon chronic renal disease. The urine is abundant, clear, of low specific gravity and contains usually some albumin, though this may be absent at a single examination. There is frequently some deformity of the legs. Renal efficiency tests show usually a striking defect of renal function. Post mortem, the kidneys are very small, granular, and grey in colour, and show excess of fibrous tissue and arteriosclerotic changes. In the accounts written by clinicians, they are spoken of as characteristic of chronic interstitial nephritis, but to the pathologist they are examples of a late stage of parenchymatous nephritis, for there is abundant evidence of previous inflammatory change. The disorder is not long compatible with life, a consideration which helps us to decide what advice should be given with regard to education.

(2) Intestinal Infantilism.-Here the smallness of body and infantilism of mind are accompanied by prominence of the abdomen and evidence of dilatation of the colon or the intestines generally. The child is probably a survivor from cœliac disease of more than slight severity in infancy, the history of which may be obtainable, and there may be a story of recurrent attacks of colitis since such an illness in the first few years of life. Some cases are probably due to congenital dilatation of the colon, or true Hirschsprung's disease.
As in the case of renal infantilism, these children are quite out of place in a school for mental defectives.

(3) Cardiac Infantilism.-Although very severe grades of mitral stenosis beginning in early life undoubtedly lead to a degree of infantilism, children with acquired heart disease seldom come up for consideration from the point of view of their mental capacity. In congenital heart disease, on the other hand, some degree of backwardness is often present. There are, of course, many cases of congenital heart malformation in which the function of the heart is perfectly good, and in which there are no symptoms whatever. Excluding these and considering only children with definite symptoms and secondary results, such as clubbing, cyanosis and dyspnœa, it is found that their mental acquirements are equal to those of average normal children of about two years junior.

Before leaving the varieties of backwardness considered from the ætiological standpoint, there are two others to which I will refer.

(C) LaCk of Self-esteem.-One of these is due to lack of self-esteem, in which the child suffers from what has come to be called the inferiority complex. The ways by which this mental state comes into being are too numerous and various to consider, but given a child with a suitable temperament, it is remarkable how small a matter may cause it to "take a back seat" as its self-appointed place. An understanding instructor, a little encouragement, or some source of selfgratulation, be it only so trivial a matter as a new suit of clothes, will sometimes awaken in such children a new interest and remove them from the ranks of the dull and backward.

(D) Late Mental Development.-The other is due to late mental development pure and simple. The child whose mind develops late, since he is not up to the usual standard for his size, we must perforce call "backward," but there is no defect, either mental or physical. $\mathrm{He}$ is merely late in beginning 
to take his first mental steps, but once started is found perhaps to be an apt learner, and soon equals or surpasses his fellows.

We have now considered very briefly some of the causes and clinical associations of dullness and backwardness in children. You will appreciate that much has been omitted, and that a large part of that which comes within our view has received but scant, even meagre, attention. I propose, however, in the concluding part of the lecture, to speak of certain children who may be brought to you because, in common parlance, they are thought by their parents or others to have something "wrong with their heads," but who are neither backward nor dull in the ordinary sense of the terms. They have certain peculiarities in their behaviour or in their attitude towards learning which draw attention to them and cause their mental qualities to be wrongly assessed. They should be recognized and distinguished from the dull. I will select a few of these unusual, but not dull, children for special discussion.

(1) Nervousness. - There are some children who are so nervous that they easily pass as ignorant or dull. If questioned, they stand transfixed with fear or make involuntary convulsive clutching movements with their hands, they go pale, they flush and sweat by turns, their mouths go dry and their tongues "cleave to the roofs of their mouths." All they know runs away, indeed they may never hear the question. Suddenly realizing that an answer is required of them, they blurt out something altogether wrong or apart from the question. As they grow older they learn more confidence and control, but they fail to do themselves credit in oral examinations. In pose they are often awkward, in gait ungainly. Even an understanding and sympathetic examiner may fail to get en rapport with them, while the hasty may misjudge them grossly, and be much surprised at their prowess when the written term examinations come to be done.
A second type of nervous child, to which Leonard Guthrie applied the term "the restrained emotional type," I cannot describe better than in his own polished and lucid style. "Emotions are strongly felt, but the powers of control are equally strong. Such children are observant, intelligent, but so reticent that they often pass for being dull, sullen and obstinate. Their expression is lowering, their attitude statuesque or stooping, their gait slouching, slow and clumsy. They are often extremely sensitive, shy and proud. They appear wanting in affection, but really yearn for it, and brood over slights, imaginary or otherwise, until they become morose, gloomy and revengeful. Being slow to take or give offence, they are often shamefully bullied at home and school, but suffer all with apparent stolid indifference, except for occasional outbreaks of fury. They are solitary in habits, introspective, prone to self-analysis, imaginative, superstitious, with morbid love of horrors, and equally morbid dread of them. They take all things seriously and have little or no sense of humour. This disposition is apt to lead to dreamy mental states and intellectual torpor, or to hysterical melancholia."

(2) Educational Overstrain. - There are children who are wrongly called "backward" because they do not fulfil some educationists' conceptions of progress. They cannot assimilate and retain a rapidly accumulating mass of facts, and the attempt leads to weariness and boredom. Facts are useful pegs on which ideas may be hung and are inseparable from education, but the best education is that which teaches how to think. Sometimes children with good intellects, capable of close and constructive thinking, have this power weighted down and smothered by being fed with masses of facts which they are expected to retain and serve up at a moment's notice. Lists of all sorts-the kings and queens, and their dates, battles, capitals and counties, \&c., ad infinitum, may be borne by some children 
with comfort, and if without advantage at least without harm, but this fact-cramming provides in others mental exhaustion and chaos, and effectually chokes such intellect and powers of thought as they possess. To some children a part of the school curriculum may be so unpalatable and burdensome that it permeates their whole school life. Some people can never spell, and will always remember the intolerable burden of attempting to learn by heart whole strings of words, many of which to them were almost or quite meaningless. Many, said Guthrie, "will sympathize with little Majorie Fleming when she wrote: 'I am now going to tell you the trouble and wretched plague that my multiplication gives me. You can't conceive it. The most Devilish Thing is 8 times 8 and 7 times 7 , what Nature itself can't endure." " Some children can concentrate on a subject for much longer than others, but must not be called either lazy or dullard-remember that even Darwin gave up the attempt to pursue his special subject for more than an hour or so at a time.

(3) Night and Day Terrors.-The child who is subject to night or day terrors is usually the reverse of stupid or dull. $\mathrm{He}$ is bright, alert, excitable, imaginative, quick in learning and ready in response. But if the terrors recur nightly or, as they sometimes do, two or three times during the night, he may go tired to school. Luckily they are not usually remembered and cause no haunting fears during waking hours, but when this happens they may colour for the time the child's whole outlook and seriously interfere with his attention to school work. Day terrors are yet more disturbing.

(4) Epilepsy.-The relationship between epilepsy and mental disorders in children is ill-defined and variable. Epileptic fits are a common symptom of all kinds of amentia. In very few do repeated epileptic fits seem to be in themselves the cause of the mental deficiency. Excluding these cases with grave mental defect, the epileptic child is usually bright, receptive and excitable. His mother will complain that his hrain is too active, that he is always reading, acquisitive of knowledge, and thinks and talks too much of school and what he learns there. $\mathrm{He}$ is not one, therefore, who would be likely to be considered dull. Should, however, he get repeated attacks of petit mal, his work at school may come under disapprobation and their cause be overlooked. There may be complaint that he goes into a brown study and pays no attention. Though quite capable of writing and spelling well, there are times when both are badly done, and no one has detected that before each period of "delinquency" there occurred an attack, perhaps marked only by fixity of expression and change in the pupils. One such child I saw recently used to appear to go into deep thought in the middle of the street, to the discomfiture of the drivers and the alarm of its mother. Others get attacks of being dazed, others unexpectedly go to sleep; yet others have "day somnambulism" from time to time. Behaviour such as this, the minor fit being so short and so little in evidence that it is overlooked, is almost certain to lead parents and masters alike to question the child's mental capacity.

(5) Speech defects may cause a child to be considered slow or backward. Stammering, stuttering, and lisping are too well known to be likely to be wrongly judged, but the treatment they receive from masters and mistresses is often calculated to make them worse. They are incidental to nervousness, and made worse by over-anxiety to avoid them. Should they be regarded as due to lack of understanding or laziness and be met by remonstrance and reproof, they will certainly become worse. Idioglossia, however, is more often attributed to backwardness, for this peculiarity in speech is less known and appears so strange to the uninitiated that the educational capacity is gravely doubted. But children with idioglossia are bright and capable, usually show no other abnormality, and almost always acquire ordinary language. 


\section{SUMMARY.}

In this lecture I have approached dullness and backwardness from the clinical point of view rather than from that of the psychologist.

Backwardness may be divided into essential (that due to primary mental defect), and non-essential (that in which the potential capacity of the mind is unimpaired).

Non-essential backwardness has been considered under four headings :-

A. That due to environment.

B. That due to physical disorders.

C. Lack of self-esteem.

D. Late mental development.

Under backwardness due to physical disorders has been mentioned that due to the following conditions:-

Sense deprivation.

Tonsils and adenoids.

Ductless gland defects.

Infantilism.

Finally, the following states have been mentioned which should be distinguished from backwardness :-

Nervousness.

Educational overstrain.

Night and day terrors.

Epilepsy.

Speech defects.

\section{HYPERTROPHIC STENOSIS OF THE PYLORUS.}

\section{By NORMAN C. LAKE,}

M.D., M.s., D.sc., F.R.C.S.,

Surgeon, Charing Cross Hospital ; Consulting Surgeon, Queen's Hospital for Children.

(Summary of Lecture to South-West London Post-Graduate Association.)

MODERN surgical literature appears to be rarely free of some reference to the treatment of that peculiar and interesting condition to which the above title is applied. The reason for this is perhaps not far to seek, for within the last ten years a profound change has occurred both in the prognosis of the disease and in the attitude which both physicians and surgeons adopt towards treatment. So rapid has been this change that many have found it difficult to accommodate themselves to the new viewpoint, and the attempt to gain a proper perspective has produced an abundant literature. Despite this fact, however, we are little further on as far as the ætiology of the condition is concerned. The two theories of origin still remain, neither being proven, the one that the condition is a congenital abnormality strictly comparable with other deformities, while the second theory assumes that the hypertrophy is secondary to spasm, brought about by irritation either in the stomach itself, or reflexly from more remote situations. When these two theories are critically examined, it is found that while some of the main facts support, others disprove each in turn. For instance, if the condition is congenital, one would expect the symptoms to start at birth, whereas there is usually a latent period of two or three weeks, which may even be extended to as many months, before the onset. Again, congenital abnormalities are apt to be multiple, but it is rarely that other abnormalities are found in association with the hypertrophied pylorus. In some thirtyfive cases only two showed any other abnormality; one a gluteal hernia, and the other a minor degree of hypospadias which could be ignored. On the other hand, if the condition is secondary to spasm, then the cause of the irritation should be demonstrable. Clinical examination, however, never reveals such, and in such cases as have come to post-mortem examination no irritative lesion has been discovered. It should here be mentioned that at one time it was held that phimosis might be the origin of a reflex irritation. It is true that the condition is coinmoner in boys than in girls; in the author's cases the proportion was nearly three to one, nevertheless, it is not extra- 